\title{
ESPACIOS PÚBLICOS, CONDICIÓN INMIGRANTE, ORDEN INSTITUCIONAL Y DERECHO A LA CIUDAD. Reflexiones a PROPÓsito de VALENCia*
}

Public spaces, immigrant condition, institutional order and right to the city.

\author{
Thoughts on Valencia
}

\section{Albert Moncusí Ferré \\ moncusi@uv.es \\ Universitat de València}

RESUMEN: Este texto aborda los espacios públicos urbanos en Valencia como contexto en el que puede construirse el derecho a la ciudad. Y lo hace con particular atención al caso de las personas de origen extranjero como sujetos de ese derecho. El texto parte de una noción de derecho a la ciudad enraizada en las obras de Lefebvre y Harvey y se centra en cuatro casos: los jardines del Turia, el debate sobre la instalación de una zona de juegos infantiles en Velluters, las calles del barrio de Els Orriols y la labor de los aparcacoches de origen extranjero en diversas zonas de la ciudad. El trabajo se contextualiza en dos ámbitos: el modelo de ciudad neoliberal y su relación con los espacios públicos urbanos, en general; y la ciudad de Valencia. La cuestión del derecho a la ciudad en los casos propuestos se centrará en el orden institucional y la razón espacial que proyectan sobre el espacio urbano las relaciones de poder. Las personas reconocidas como «inmigrantes» encarnan esa proyección de manera especial. La reflexión termina con una propuesta de apertura hacia un orden de la interacción en el que ésos y otros sujetos pueden construir vías de acceso al derecho a la ciudad.

Este texto se nutre de las reflexiones teóricas y del trabajo de campo emanados de los proyectos «Metrópolis glocalizadas: el caso de Valencia. Espectacularización y precarización urbana en las ciudades medianas» (micin CSO2009-10715), «Convivencia y barrios multiculturales. Conflicto y cohesión en una España en crisis» (Convocatoria I+D+I del Ministerio de Ciencia e Innovación 2014-2017 Ref. cso 2014-54487-R) y «El vecindario Romá y los inmigrantes que ejercen de aparcacoches en Valencia. Economía informal, vivienda precaria e inmigración en la ciudad de Valencia» (contrato del Ayuntamiento de Valencia). 
Palabras clave: derecho a la ciudad, espacios públicos urbanos, condición inmigrante, orden institucional, Valencia.

ABSTRACT: This text explores urban public spaces in Valencia as a context in which to build the right to the city, paying particular attention to the case of people of foreign origin. The paper starts from the notion of the right to the city rooted in the works of Lefebvre and Harvey, and centres on four cases: the Jardines del Turia, the debate on the installation of a children's play area in Velluters, the streets of the neighbourhood of Els Orriols, and the work of people of foreign origin who help drivers find parking spaces in various parts of the city. The study is contextualised in two fields: the neoliberal city model and its relationship with urban public spaces, in general; and the city of Valencia. The question of the right to the city in these cases centres on the institutional order and spatial reason that project power relationships on the urban space. People recognised as "immigrants" embody this projection in a special way. The reflection concludes with an opening proposal for interaction in which people of foreign origin and other citizens can develop ways of accessing the right to the city.

KEYWORDs: Right to the city, urban public spaces, migrant condition, institutional order, Valencia.

RESUM: Aquest text aborda els espais públics urbans a València com a context en el qual pot construir-se el dret a la ciutat. I ho fa amb particular atenció al cas de les persones d'origen estranger com a subjectes d'eixe dret. El text parteix d'una noció de dret a la ciutat arrelada en les obres de Lefebvre i Harvey i se centra en quatre casos: els jardins del Túria, el debat sobre la instal-lació d'una zona de jocs infantils a Velluters, els carrers del barri dels Orriols i la tasca dels aparcacotxes d'origen estranger en diverses zones de la ciutat. El treball es contextualitza en dos àmbits: el model de ciutat neoliberal i la seva relació amb els espais públics urbans, en general; i la ciutat de València. La qüestió del dret a la ciutat en els casos proposats es centrarà en l'ordre institucional i la raó espacial que projecten sobre l'espai urbà les relacions de poder. Les persones reconegudes com «immigrants» encarnen eixa projecció de manera especial. La reflexió acaba amb una proposta d'obertura cap a un 
ordre de la interacció en el qual eixos i altres subjectes poden construir vies d'accés al dret a la ciutat.

Paraules clau: dret a la ciutat, espais públics urbans, condició immigrant, ordre institucional, València.

\section{Introducción}

$\mathrm{E}$ 1 derecho a la ciudad es un tema nuclear en los estudios urbanos, desde que lo formuló Lefebvre (1969[1968]) como derecho a la vida urbana, con una especial incidencia en la capacidad de producir simbólicamente lugares de encuentro, dando prioridad al valor de uso, por encima del valor de cambio y resaltando aspectos culturales y sociales, más que aspectos relativos específicamente a la morfología urbana. Más tarde, Harvey (2003) lo definió como la posibilidad de intervenir en las ciudades, para modificarlas, frente al constreñimiento que representa su apropiación por el capital y aquellos proyectos que la instrumentalizan para su comercialización y su explotación económica en aras de intereses de clase y lecturas individualistas, fundamentalmente a través del negocio inmobiliario y del marketing urbano.

A partir de ahí, el derecho a la ciudad se puede entender como la posibilidad de acceder a la producción colectiva de lo urbano, en oposición al urbanismo neoliberal porque, al amparo de éste, se trataría no de un derecho ciudadano sino del privilegio de unos pocos. En principio es una posibilidad confeccionada en usos y prácticas cotidianos, pero también, sobre todo, en movilizaciones sociales y definición de formas de gobernanza social de lo urbano. En los espacios públicos urbanos se puede hacer particularmente visible esa posibilidad creativa, porque acogen esas prácticas y son escenario de movilizaciones sociales y porque, además, se plasman en ellos intervenciones urbanísticas que resultan del ejercicio de nuevas formas de gobernanza. Sin embargo, pueden ser también escenario en el que se instituyen privilegios de ciudadanía, empezando por la misma presencia en esos espacios. Y es que se trata de ámbitos regulados administrativamente (y, por lo tanto, objeto de institucionalización desde el gobierno) y en ellos se constituye lo urbano, 
siempre inacabado (Delgado, 1998). Ahí es posible, al mismo tiempo, construir ciudadanía (entre otras cosas, capacidad de acceso, presencia y actividad en la ciudad) y producir exclusión (negación de aquel acceso, presencia y actividad), pues es donde se ejercen relaciones de poder, dominación y también resistencia. Los espacios públicos son como el corazón de la vida urbana y cuando en ellos se materializa la exclusión o si son privatizados, es como si la ciudad se disolviera. Y no sólo porque se coarta la libertad de estar o actuar, sino también porque en esos espacios es donde se producen movilizaciones públicas que reivindican servicios y derechos de la ciudadanía (Borja, 2011).

El espacio público se construye como tal a través de la posibilidad de trato con distintos sujetos, de sus movimientos y de la mayor o menor negociación de distancias. Los espacios públicos entrañan una igualdad potencial y la posible apertura a actores diversos y usos plurales (Tonnelat, 2010). El sentido de estos espacios proviene de sus ocupaciones y usos múltiples y transitorios, por lo que es intrínsecamente diverso (Segura, 2013). En un mismo espacio pueden, entonces, producirse distintas concentraciones temporales de sujetos que generan diferentes microclimas de sociabilidad (Delgado, 1998).

Sin embargo, el acceso a los espacios públicos y las prácticas que pueden desarrollarse en ellos están sujetos a reglas. Las más elementales son la urbanidad y el anonimato que garantizan una cierta experiencia de libertad sin intromisiones; esa indiferencia cortés o inatención cívica de las que hablaron, respectivamente Simmel (1986[1908]) y Goffman (1963) como átomo de lo urbano. Si bien a priori la ciudadanía conlleva compartir esa regla básica en los espacios públicos, los sujetos ocupan una posición a partir de relaciones de desigualdad y dominación y son objeto de prácticas de control.

La conjunción de diferencias en el espacio público muestra la diversidad característica de lo urbano en distintos terrenos y, entre ellos, el étnico. Sucede, por ejemplo, con la llegada de nuevos residentes desde el extranjero. Nuevos y viejos residentes creen compartir o no ciertos rasgos, en especial descendencia y/o cultura, definidos desde fuera o por parte de sus propios miembros. Entonces, la ciudadanía puede transitar por el espacio público, pero no a todo el mundo se le reconoce automáticamente ese derecho. $\mathrm{La}$ ansiedad o el sentimiento de extrañeza pueden contribuir a construir metonímicamente el espacio en asociación con categorías étnicas o raciales e incluso 
se criminaliza a quien es diferente (Keith, 2009). El espacio público puede acabar siendo vetado a quienes se considera originan esos sentimientos, con controles policiales por perfil étnico y discursos públicos sobre apropiaciones indebidas. A quienes son reconocidos como «étnicos» les puede ser difícil pasar desapercibidos y, por lo tanto, pierden el derecho a la indiferencia que entraña la ciudadanía (Delgado, 1999).

Este texto invita a reflexionar sobre la ambivalencia de los espacios públicos y la fragilidad del derecho a la ciudad, con especial atención a manifestaciones de diversidad étnica. Una propuesta anclada en la ciudad de Valencia y, más específicamente, a partir de cuatro casos: los jardines del Turia, el debate sobre la instalación de una zona de juegos infantiles en Velluters, las calles del barrio de Els Orriols y la labor de los aparcacoches de origen extranjero en diversas zonas de la ciudad. La base empírica de este trabajo es la investigación desarrollada, en Valencia, en distintos momentos, desde hace más de diez años, mediante entrevistas y observación. ${ }^{1}$

Empezaremos esta invitación con dos apartados de contextualización. El primero se referirá al modelo de ciudad neoliberal y a su relación con los espacios públicos urbanos. El segundo apartado presentará algunos datos sobre la ciudad de Valencia. Cerrará este texto un análisis de los casos propuestos, a la luz de la cuestión del derecho a la ciudad.

\section{El urbanismo neoliberal: disposiciones, huella cultural y des- contentos}

Comprender cualquier fenómeno urbano requiere tener en cuenta el urbanismo neoliberal que ha dominado las ciudades desde el último cuarto del siglo xx. Para sintetizar su significado podemos acudir a Brenner y Theodore (2005), para quienes se trata de un proceso de intervención en las ciudades, orientado al mercado, que articula estrategias de transformación institucional y rearticulación ideológica. Es una intervención protagonizada por agentes privados, pero activamente promovida por poderes públicos y que tiene una

1. Sobre los jardines del Túria en general, véase Moncusí y Llopis (2012) y Moncusí y Hernández (2013). Sobre Els Orriols, puede consultarse Torres y Moncusí (e. p.). Por lo que se refiere a los aparcacoches, ver Moncusí y Pérez (2016). En el caso de Velluters, ver Benlloch (2016) y Benlloch, Fioravanti i López (e. p.). 
concreción distinta, en cada ciudad. Los mismos autores sugieren que, lejos de lograr un sólido y continuo éxito, el modelo desemboca en fracasos en los terrenos financiero, administrativo y de gobernanza y que encuentra oposición en fuerzas sociales que tratan de preservar formas de organización y coordinación ajenas al mercado y a la libre acumulación de capital financiero.

De forma diferente, en distintas zonas de cada ciudad, y de forma particular en cada urbe, la fórmula del urbanismo neoliberal (Cucó, 2013) se ha materializado en los espacios públicos urbanos y en la posibilidad de ejercer, en ellos, el derecho a la ciudad. Se realizan inversiones urbanísticas resultado de una especulación convenientemente precedida de la construcción de un entorno degradado que permite generar plusvalía. Se construyen viviendas, negocios y centros comerciales con derecho de admisión, con beneplácito o colaboración municipal o, como mínimo, permisividad legislativa, especulación y ganancias de la plusvalía (Borja, 2011). Se trata de operaciones que pasan por el desplazamiento de población residente fuera del barrio, por no poder acceder a unas viviendas encarecidas (Benlloch, 2016). Además, el incremento de los precios de la vivienda va de la mano de una homogeneización urbanística, dirigida al consumo, y una pérdida de autenticidad, en términos de organización de la vida cotidiana, capacidad de construcción de la ciudad por sus propios ciudadanos, conciencia de las propias raíces y posibilidad de seguir viviendo y trabajando donde uno lo hacía (Zukin, 2009). En este sentido, el desplazamiento no es sólo físico, sino también simbólico, en la medida en que se resignifica el entorno urbano.

En cuanto a los espacios públicos urbanos, son objeto de mercantilización, fruto de la necesidad de expandir el capital y del recurso a la externalización de costes de mantenimiento (Leal y Leyva, 2011). Se destinan unos fondos al cuidado de parques, calles, plazas y jardines que no sólo son menores, sino que además sirven al beneficio de agentes privados (Low, Taplin y Sheld, 2005). Puede ocurrir, además, que espacios que eran gratuitos pasen a ser usados solamente por quienes paguen un precio. En el caso de las nuevas viviendas, se ofrecen espacios de uso exclusivo para residentes de uno o varios edificios. En otros casos, se cercan espacios anteriormente abiertos. Es una mercantilización y una privatización del espacio que conlleva seleccionar usuarios para que respondan a un perfil de «clase media» (Aramburu, 2008); 
el mismo al que van dirigidas intervenciones urbanísticas que incluyen, entre otras, construir vallas o aplicar normativas que restringen usos (Low, Taplin y Sheld, 2005).

Este urbanismo tiene como consecuencia que calles animadas y abiertas se vacíen de vida al tiempo que se llenan grandes centros comerciales y se olvida e incluso se criminalizan esas calles. Los comercios locales cierran y hay poco que hacer por las calles al margen de transitar por ellas. Ese proceso de vaciado puede ser la antesala de una gentrificación que acaba desplazando a los sectores populares que habitaban una zona, para acabar acogiendo nuevos vecinos de clase más acomodada. De este modo, el miedo a los otros y la obsesión por la seguridad conforman un discurso que acompaña a dinámicas urbanas excluyentes y que justifica prácticas especulativas (Borja, 2011).

La ciudad neoliberal, como marco, está presente en la realidad de los espacios públicos urbanos, en barrios y en zonas emblemáticas de las ciudades, y también en los imaginarios sobre la ciudad como espacio deseable o no. Sin embargo, si lo visto hasta aquí parece un relato donde hay un mal claramente contorneado, la realidad dista mucho de ser tan clara. Si la lógica del mercado se ha institucionalizado puede decirse que este urbanismo tiene fundamentos culturales que resulta complicado rehuir y que se traducen en claroscuros a la hora de aproximarse a los espacios públicos urbanos.

\section{Valencia: del modelo neoliberal a la gobernanza participativa, pasando por los espacios públicos urbanos}

Entre el cierre del siglo xx y el inicio de la última crisis económica, en 2008, Valencia y su área metropolitana pasaron por un tsunami urbanizador (Gaja, 2006). Se produjo una expansión inmobiliaria sin precedentes, facilitada por la Ley reguladora de la actividad urbanística de 1994 y con el protagonismo de oligopolios privados que hicieron de agentes urbanizadores con la colaboración o, como mínimo, el beneplácito del sector público (Sorribes, 2015). La desigualdad entre ciudadanos se vio potenciada y ocurrió lo propio con la desintegración urbana, tanto en la esfera metropolitana como en la barrial (Cucó, 2013). 
Fue un periodo de excesos con consecuencias que han sido observadas en barrios periféricos, centrales y semicentrales y en el área metropolitana, con servicios deficitarios, falta de infraestructuras y una escasa articulación metropolitana (Santamarina y Moncusí, 2013). Todo ello, a pesar de las movilizaciones protagonizadas por vecinas y vecinos, para mejorar la situación, sobre todo en barrios populares (Ruiz y García Pilán, 2013; Santamarina, 2016; Cucó, 2016). Esas mismas zonas han sido elegidas para la construcción de viviendas dirigidas a población acomodada. Ha sido el caso de Nuevo Orriols (adyacente a Els Orriols), Sociópolis (en Nazaret) o La Marina Real (al lado de la Malvarrosa) (Sorribes, 2015; Cucó, 2016). En los barrios centrales y semicentrales intervenciones de renovación han conllevado la expropiación a antiguos residentes y de su manera de habitar la ciudad (Benlloch, 2016; Hernández y Torres, 2013 y 2015).

Algunos de esos residentes, sin embargo, no eran tan antiguos. El encarecimiento del suelo y la planeación para nuevos usos ha desplazado a población de origen extranjero y, sobre todo, ha dificultado que se incorporen nuevos vecinos con recursos más limitados, entre los que se encuentra población de origen extranjero. Ésta ha experimentado en Valencia un considerable incremento en lo que va de siglo. Si en el año 2000, un 2,6\% de población era de origen extranjero y un 1,1\% de población extranjera, en 2016 quienes nacieron en el extranjero eran un $16,7 \%$ y las personas de nacionalidad extranjera un $12,2 \%$, respectivamente. Los nuevos vecinos se fueron insertando en la ciudad sin grandes concentraciones, empezando por barrios centrales y semicentrales. Con todo, a lo largo de los últimos quince años, han ido ganando presencia en los barrios de la periferia obrera, mientras barrios otrora con mayor proporción de población extranjera experimentaban un descenso de porcentaje de residentes foráneos y un progresivo proceso de gentrificación. Si en el año 2002 eran los céntricos El Pilar y el Mercat los barrios con mayor proporción extranjera (entre el 2 y el 3\%), en 2016, la mayor presencia se da en barrios periféricos como Els Orriols, Tres Forques, La Fontsanta, el Calvari o la Roqueta, con una proporción de población extranjera entre el 18 y el 21\% (aunque El Pilar se mantiene entre los seis barrios con mayor porcentaje de población extranjera). 
El barrio con mayor proporción de población extranjera (Els Orriols) tiene un $21,7 \%$ de población de ese perfil y es, también, el que tiene mayor porcentaje de población nacida en el extranjero (28,3\%). Algunas zonas del barrio presentan concentraciones superiores al $40 \%$ de población originaria del extranjero. Con todo, se trata de personas de distintas nacionalidades y, además, en todos los casos la población española es claramente mayoritaria. Por lo tanto, no estamos hablando de segregación urbana sino de una concentración relativa en el contexto de la cual existen oportunidades potenciales de contacto interétnico. En el conjunto de la ciudad, las relaciones en espacios públicos y servicios públicos han mostrado un carácter tranquilo, al margen de algunas manifestaciones de extrema derecha (Torres, 2007; Torres, Moncusí y Esteban, 2015).

La diversidad de usos de los espacios públicos es un claro exponente de esa dinámica tranquila de incorporación a la ciudad y en Valencia es palpable en barrios concretos y en espacios públicos emblemáticos como los jardines del Turia o el paseo marítimo, aunque en el primer caso - como veremos después - se produzcan situaciones de uso exclusivo (Torres, 2005) y a pesar de que algunos sujetos ven dificultado su acceso al espacio público o el hecho de moverse por él. Una dificultad que puede tener su raíz en una situación de carencia de recursos económicos y verse agudizada cuando puede pesar sobre los sujetos la sospecha de ser «inmigrantes» en situación irregular.

Un último apunte de contexto resulta fundamental. Se trata del cambio político que se produjo en el gobierno local tras los comicios de mayo de 2015. El cambio de signo político ha supuesto un viraje hacia la participación y la intervención integral. Así, se han desplegado iniciativas que conllevan una gobernanza local participativa, con implicación de organizaciones y universidades, incorporación de técnicos, elaboración de presupuestos y planes participativos. En tres casos, además (Benimaclet, Nazaret y Els Orriols) se ha actuado con la finalidad de elaborar un plan de intervención integral. Un ejemplo de prácticas desarrolladas desde el nuevo gobierno son los presupuestos participativos. En la última edición, en 2017, las distintas opciones se fueron seleccionando por distrito, según disponibilidad presupuestaria. El consistorio acordó distribuir los fondos según la ratio de población residente, en cada distrito y también atendiendo a la renta media y a las dotaciones 
previas existentes en cada caso. Se conformaron grupos de trabajo en cada distrito, con participación de población de cada uno de ellos, individual o a través de asociaciones, y con implicación de las juntas de distrito. Se podía votar cualquier propuesta, independientemente del distrito en el que se residiera y las propuestas nacían de los grupos de trabajo, pero también se aceptaron iniciativas que vinieran avaladas por 30 vecinos/as. Cabe apuntar que Rascanya fue el distrito con mayor dotación $(6,9 \%$ de los $7000000 €$ asignados) y Ciutat Vella el que obtuvo menos (2\%). La siguiente tabla recoge las propuestas planteadas para su ejecución en 2017:

Tabla 1.

Propuestas programa presupuestos participativos «DecidimVLC» 2017. Fuente: Elaboración propia a partir de datos de la web decidimVLC.

\begin{tabular}{|l|c|c|c|}
\hline Tipología & Distritos & Total votos & Presupuesto \\
\hline Acondicionar plazas o calles & 5 & 1706 & $236.002 €$ \\
\hline Asfaltado & 2 & 414 & $245.231 €$ \\
\hline Bancos & 4 & 773 & $311.469 €$ \\
\hline Carril bici & 11 & 3367 & $2.147 .183 €$ \\
\hline Huertos urbanos & 2 & 728 & $562.332 €$ \\
\hline Iluminación & 4 & 181 & $180.628 €$ \\
\hline Instalaciones deportivas & 8 & 2218 & $1.859 .427 €$ \\
\hline Jardines & 2 & 894 & $286.785 €$ \\
\hline $\begin{array}{l}\text { Paneles informativos asociaciones o activi- } \\
\text { dades }\end{array}$ & 2 & 410 & $40.708 €$ \\
\hline Parques & 9 & 2592 & $1.467 .892 €$ \\
\hline Parque perros & $\mathrm{I}$ & 496 & $287.01 \mathrm{I} €$ \\
\hline Pasos peatones & $\mathrm{I}$ & 252 & $21.000 €$ \\
\hline Patrimonio histórico & $\mathrm{I}$ & 490 & $32.283 €$ \\
\hline Rehabilitación edificio público & $\mathrm{I}$ & 503 & $55.283 €$ \\
\hline Reurbanización o mejora calle & 5 & 1142 & $707.682 €$ \\
\hline Sonómetros & $\mathrm{I}$ & 248 & $0 €$ \\
\hline Vial, anillo peatones o aceras & 5 & 1293 & $299.305 €$ \\
\hline
\end{tabular}

La opción que aparece en más distritos son las intervenciones relacionadas con la apertura o remodelación de carriles bici. Es también lo más 
votado. Según se indicó en prensa (Las Provincias, 18 abril 2017), ocho de esas propuestas llegaron por particulares con el aval de treinta personas y tres lo hicieron por grupos de trabajo. En segundo lugar, se encuentran las intervenciones en parques y en tercera posición las instalaciones deportivas. $\mathrm{La}$ movilidad y el ocio en el espacio público urbano aparecen, así, como aspectos a los que se otorga la mayor importancia, sea desde los distritos directamente o por parte de colectivos ciudadanos. En una valoración sobre los proyectos que iban a ser objeto de consulta, el concejal de participación afirmó que las propuestas «indican que la gente quiere una ciudad más sostenible y amable con las personas» (Levante, 9 de febrero de 2017). Los espacios públicos urbanos parecen estar, pues, en el centro de la intervención gubernamental y los intereses del vecindario. Podría decirse que ello garantiza una disposición positiva hacia el derecho a la ciudad. Por una parte, por la toma colectiva de decisiones y, en segundo lugar, por abordar un ámbito central de la construcción democrática de la ciudad, como son los espacios públicos urbanos. Sin embargo, sin ánimo de negar esto último rotundamente, se intuyen algunos claroscuros tras estas propuestas. La toma colectiva de decisiones se realiza sin que necesariamente se conozca la viabilidad técnica de las propuestas, la posibilidad de valorar distintas soluciones técnicas a un mismo problema y con limitaciones presupuestarias que condicionan las posibilidades de llevarlas a cabo. Además, pese a la apertura a la participación, puede que haya colectivos que queden fuera del proceso participativo por desconocimiento, falta de recursos lingüísticos o desconfianza en los resultados del propio proceso. A todo ello cabe añadir que los espacios urbanos no siempre están plenamente abiertos a un uso en igualdad. Veámoslo a continuación, en tres ejemplos.

\section{El derecho a la ciudad en espacios públicos urbanos y la condi- ción inmigrante}

La amabilidad a la que apelaba el concejal de participación concuerda con lo que Giménez (2005) llamó coexistencia o lo que Torres (2008) consideró convivencia pacífica, pero distante. Se trata de que los espacios públicos urbanos constituyan lugares en los que se evita toda fricción sobre una base 
tácita de aceptación de la mutua presencia y movimientos. Pero puede también integrar un ideal de civismo que parte de la reificación de la noción de espacio público. Ésta se produce, según Segura (2013), cuando se idealizan las bondades de la existencia de parques y plazas, como quintaesencia de la definición de interacciones positivas. Esta concepción reificada es coherente con lo que De la Haba y Santamaría (2004) denominaron «razón espacial». Se trata de una suerte de ordenación de espacios y sujetos basada en las bondades de la mezcla y la diversidad y los perjuicios inherentes a cualquier concentración de gente de un mismo perfil y que plantea proyectos urbanísticos como solución técnica, en detrimento de valorar la creatividad de los usuarios de los espacios y partir de la complejidad de las prácticas sociales. Sin embargo, ¿podemos decir que esa razón garantiza, en la práctica, el derecho a la ciudad?

Podemos pensar que el derecho a la ciudad es garantizado en un cierto marco de régimen de protección y de atribución de aquello que puede ser reclamado y de lo que puede ser practicado con base en un estatus reconocido. En el caso de las personas inmigradas del extranjero, se ha observado una estratificación cívica sobre una institucionalización de la ciudadanía en condiciones de desigualdad económica y social (López Sala, 2006). Se trata de que un régimen $u$ orden institucional diferencie grados de acceso a los derechos para distintos sujetos ¿Cuál sería ese orden institucional? Sería aquel orden público basado en leyes y reglamentos y que se diferencia de un orden interaccional, basado en acuerdos tácitos (Tonnelat y Milliot, 2013). En primera instancia, puede decirse que el derecho a la ciudad es garantizado en el marco de ese orden: 1) en el que se diferencia a los sujetos (pudiendo incluso estigmatizarlos); 2) donde se delimitan marcos de acción e incluso espacios físicos, se define y sanciona lo que se considera un comportamiento correcto o incorrecto; 3) que es aprehendido por los sujetos como un marco de seguridad que, si se percibe puesto en duda, saca a relucir miedos.

Podemos encontrar varios ejemplos de estos tres aspectos del orden institucional. En primer lugar, en cuanto a la diferenciación e incluso estigmatización de los sujetos e incluso de zonas urbanas enteras, es algo que sufren personas calificadas como «inmigrantes» y sospechosas de encontrarse en situación irregular y que son, por ello, objeto de controles policiales de identificación. Esta práctica puede contribuir a que «inmigración»e «ilegalidad» se asocien y, además, genera entre aquellos nuevos vecinos el temor a ser 
detenidos y confinados en centros de internamiento y a ser, finalmente, extraditados. Un temor que conlleva recluirse frente a la amenaza y, por lo tanto, retirarse del espacio público. Así, se produce una diferenciación de sujetos con menos derechos que otros a transitar por el espacio público o a estar presentes en él.

Lo que acabamos de ver está en consonancia con un segundo aspecto característico del orden institucional: supone una tarea de delimitación de marcos de acción e incluso espacios físicos con sanciones sobre lo que se considera un comportamiento correcto o incorrecto. Un ejemplo lo encontramos en el caso de personas extranjeras que ejercen como aparcacoches en las calles de Valencia. Algunas de ellas experimentan controles de identificación como sospechosas de residir en España, en situación irregular. Además, su actividad es objeto de control, como tal, sobre la base de ordenanzas municipales, aplicadas independientemente de si el aparcacoches es identificado como inmigrante extranjero. Se han impuesto sanciones, desde 2008, por invasión de la calzada, usurpación de cargo público en materia de tráfico y desobediencia a agentes de la autoridad. ${ }^{2}$ En 2010 se aprobó la Ordenanza de Circulación, que entró en vigor en julio de ese mismo año (Las Provincias, 12 de julio de 2010). Infracciones de tráfico y resistencia a la autoridad motivaban infracciones, cuando se indicaba a los aparcacoches que abandonaran su actividad y éstos no lo hacían. Como ordenanzas similares de otras ciudades, la que se refiere a la circulación de la ciudad, por un lado, incluye la prohibición de la labor de aparcacoches en ordenanzas llamadas "de convivencia", junto a mendicidad, prostitución o botellones ${ }^{3}$. Por otro lado, se aborda la cuestión desde el punto de vista del tráfico y la circulación, posición en la que encontramos al Ayuntamiento de Valencia. Este perfil normativo conlleva cierto

2. En 2008, se tramitaron 1142 denuncias a aparcacoches y 1017 hasta agosto 2009, por infracción del artículo 122 del Reglamento General de Circulación “al permanecer en la calzada con grave riesgo para la circulación y para su propia integridad física". La reiteración conllevaba denuncia por desobediencia y se remitía a Fiscalía, donde solía archivarse (Europa Press, 17/08/2009).

3. Por ejemplo, existen este tipo de ordenanzas en Castellón, Xàbia, Altea, Vila-real o Calpe. En este último caso, se menciona la prohibición de "la actividad de aparcacoches, conocidos vulgarmente como «gorrillas»" en el capítulo 5.2 de la ordenanza de Limpieza Viaria y Residuos Sólidos, en un apartado sobre "mendicidad en vía pública". 
reconocimiento a una función de regulación de tráfico y aparcamiento en la vía pública que realizan los "gorrillas".

En el caso de Valencia, que la ordenanza no sea llamada "de convivencia" le resta valor moralizante, pero se aplica un enfoque disciplinario hacia la actividad de aparcacoches y de quienes la realizan, que se ha visto agravado por la desaparición de las faltas en la reforma del código penal de 2015 que ha conllevado que ante la desobediencia se pase a aplicar la Ley de Seguridad Ciudadana (Ley Orgánica 4/2015, de 30 de marzo, de protección de la seguridad ciudadana, conocida como "ley mordaza"). La desobediencia a la autoridad se tipifica en esa ley como falta grave (artículo 36). Es algo que experimentan los sujetos, independientemente de su origen étnico, pero que la exposición al control se ve acentuada cuando el color de la piel denota la posible condición migrante.

El orden institucional, sin embargo, no es únicamente policial. Un ejemplo de ello lo encontramos en el caso de los jardines del Turia, de Valencia. En 2002, la federación de AAVV de la ciudad se quejó porque inmigrantes de origen latinoamericano monopolizaban zonas del parque, para actividades deportivas, pero también para prácticas de ocio que generaban suciedad, degradación e inseguridad. La situación se resolvió con intervención de la propia federación, la asociación de ecuatorianos y la policía local. Posteriormente, se fue produciendo una acomodación de actividades deportivas organizadas por migrantes de Bolivia y Ecuador, pero también una intervención arquitectónica que las condicionó (Torres, 2009; Moncusí y Llopis, 2012), en un ejemplo de cómo una intervención arquitectónica en los espacios contribuye a ordenar prácticas y delimitar usos y ocupaciones normalizadas. La construcción de equipamientos deportivos, parques infantiles, bancos, papeleras o vallas y puertas ha cumplido ese papel, en el parque de los jardines del Turia (Moncusí y Hernández, 2013). Por ejemplo, en 2002 había cinco terrenos para jugar a futbol, de tierra y delimitados por una simple barrera. Hoy sólo quedan dos campos que están cercados, su terreno con césped artificial y su entorno equipado con banquillos, gradas y vestuarios. Un parque infantil ocupa el espacio de otro de los antiguos terrenos de juego. Se da el caso de que las antiguas canchas eran usadas por clubes, con autorización municipal pero que también se celebraban allí ligas organizadas por asocia- 
ciones de ecuatorianos y bolivianos, en virtud de un acuerdo de subarriendo de los campos. Ese uso ha quedado marcadamente restringido y sus protagonistas (sobre todo inmigrantes procedentes de aquellos dos países Latinoamericanos) han acabado siendo desplazados fuera del parque o han tenido que desarrollar otras actividades. Con ello, se ha limitado también la realización de otras prácticas que allí se producían, como la venta ambulante. La institucionalización supone un afán regulador que, aunque no sea abiertamente aplicado contra inmigrantes de origen extranjero, tiene efecto sobre el despliegue de prácticas por parte de éstos.

Cabe añadir, a todo esto, lo que De la Haba y Santamaría (2004) denominaron control administrativo o burocrático del acceso al espacio público. Se trata de recurrir a instrumentos de financiación y autorización de actividades que permiten acceder al uso del espacio, desde un estatus de ciudadano reconocido y desde el conocimiento de mecanismos que otros sujetos desconocen. Es lo que se despliega, por ejemplo, en el caso de la ocupación de la vía pública por fiestas tradicionales o en el desarrollo de actividades comerciales en la calle.

Pero, si el orden institucional permite diferenciar sujetos y delimitar espacios y sus usos, acaba siendo también percibido por los sujetos como un marco de seguridad. Encontramos en el barrio valenciano de Els Orriols, un ejemplo de ello. Allí la presencia policial se ha producido no solo con controles a personas de tez oscura sino también por las quejas vecinales asociadas a ruidos, atracos y suciedad producidas por algunas personas alojadas de manera regular o irregular en pisos de un par de calles de la zona más humilde del barrio, conocida como Barona. La asociación de vecinos del barrio ha reclamado una intervención municipal e incluso la creación de un retén (Las Provincias, 30 de junio de 2016). Son calles en las que han cerrado comercios y de bloques de pequeños pisos, sin ascensor y algunos afectados de aluminosis. Esta misma zona era asociada a las drogas y a la delincuencia. La situación social del barrio ha motivado que sea incluido en el Atlas de Vulnerabilidad Urbana de España y ha justificado un estudio para un plan de intervención integral. Aunque el barrio alberga diversas realidades y muchas más calles en las que la vida transcurre con una calma perceptible habitualmente sobre un fondo de una animada vida comercial, es objeto de una estig- 
matización espacial que limita la interacción entre personas, en la medida que lleva a una prevención al contacto en espacios públicos, sobre una percepción de miedo. Ello, además, refuerza el valor de la seguridad como aspecto fundamental a la hora de valorar los espacios públicos.

Otro ejemplo pone de manifiesto la aprehensión del orden institucional por parte del vecindario y su consiguiente participación en actuaciones que lo reafirman. Hemos visto antes las medidas propuestas para presupuestos participativos. En Velluters, fue controvertida la propuesta de instalar unos juegos infantiles en calles de Ciutat Vella en las que se ejerce la prostitución. Mientras la asociación de comerciantes del centro histórico afirmaba que esa medida alejaría a las prostitutas, el colectivo social Escoltem Velluters sostenía que semejante justificación contravenía los principios del proceso participativo. La propuesta acabó siendo aprobada como la más votada del distrito de Ciutat Vella, a partir precisamente de ese argumento de intervención reguladora (Levante, 7 abril de 2017).

En este orden institucional, el miedo actúa como elemento relacionado con espacios, tiempos y rostros y entra en juego como «poderoso regulador de los usos de la ciudad y, por ende, de la densidad del espacio público urbano», al tiempo que reglamentaciones y regulaciones más o menos explícitas «prescriben o proscriben acciones y usos, delineando un acceso desigual al espacio urbano» a modo de «estructura de interacción» que «supone que hay un tiempo para cada cosa; una estructura que los sujetos definen, a partir de su situación social y espacial; de sus relaciones, conflictos y evitaciones» (Segura, 2013).

\section{A modo de cierre}

A partir del modelo neoliberal y a pesar de los intentos por superarlo mediante un urbanismo participativo, el derecho a la ciudad sigue siendo algo que no está al alcance de la mano de quienes habitan la urbe. Los espacios públicos urbanos albergan un enorme potencial a la hora de construir vías de acceso a ese derecho. Hemos visto, por ejemplo, su considerable peso entre las propuestas de presupuestos participativos de Valencia, en 2017. Sin embargo, al mismo tiempo, el orden institucional que los regula acaba delimitándolos y dibujando una estratificación entre quienes pueden o no acceder 
plenamente al derecho a la ciudad o, por lo menos, entrar en esos espacios o moverse por ellos.

Una razón espacial supone la ordenación de espacios y sujetos y una reificación de la arquitectura del espacio público como solución, en especial en la figura de parques y plazas. Esa razón pone de manifiesto un orden institucional que conlleva distintos grados de acceso al derecho a la ciudad, con la estigmatización de algunos sujetos y su presencia pública. Es el caso de los migrantes cuyos rasgos físicos denotan condición de extranjeros $\mathrm{y}$, en especial, cuando están en en situación irregular. Mientras tanto, otros ven garantizadas expectativas de seguridad y confortabilidad. Es un orden institucional donde la seguridad y el miedo ocupan un lugar fundamental, especialmente en contextos de crisis como el reciente.

Sin embargo, existe también un orden interaccional de acuerdos tácitos intersubjetivos. Plataformas y organizaciones vecinales, redes y movimientos ciudadanos y asociaciones de distinto tipo (también en el contexto policial) ocupan un lugar en él y en lo que puede ser una vía de construcción de una nueva institucionalidad que amplifique el derecho a la ciudad. Las propuestas de presupuestos participativos son una aportación en este sentido, en relación con el acceso a los espacios públicos urbanos. Sin embargo, un cambio más profundo puede surgir desde una participación ciudadana que vaya más allá de lo deliberativo, en la medida en que lleve el consenso comunitario al diseño y los usos de los espacios. Existen algunos casos en este sentido. La construcción de un parque en el descamado de la ermita de San Jerónimo, que se está realizando en el barrio valenciano de Els Orriols, por ejemplo, partió de una demanda comunitaria previa y de una dinámica preexistente a un proceso participativo realizado en el barrio con apoyo municipal. Otros ejemplos son los que han surgido del proyecto de intervención comunitaria intercultural (ICI), realizado en varias ciudades españolas, con actuaciones como el diseño consensuado, por jóvenes, de la zona multideportiva de Playa Honda, en el municipio Canario de San Bartolomé o la acción ciudadana Comparkte que ha puesto sobre la mesa nuevos usos del parque Arriaga, en Pueblo Nuevo (Madrid) (Giménez, 2015). Otra línea de trabajo son las cartografías participativas desarrolladas en varias localidades de Chile que permiten identificar usos y vacíos en la ciudad para una posterior acción política (Zambra-Álvarez 
y otros, 2015). Un papel activo y reconocido en el diseño y los usos plurales de los espacios, resulta fundamental en estos casos y abre la puerta a la institucionalización de espacios de encuentro y permite conjugar el derecho a la ciudad, desde el pluralismo étnico. Si todo ello se ve acompañado de prácticas institucionales y dinámicas socioeconómicas que eviten discriminaciones y que incidan en la igualdad de recursos, el derecho a la ciudad puede verse decisivamente ampliado.

\section{Bibliografía}

Aramburu, M. (2008). «Usos y significados del espacio público». $A C E$. Arquitectura, ciudad y entorno: 8, pp. 142-150.

Benlloch, Ll., Fioravanti, H. i López Nicolás, M. (e. p.). «Respostes veïnals davant del conflicte al voltant de les treballadores del sexe del barri Xino de València». En A. Moncusí, F. Torres i H. Fioravanti (Eds), Barris i ciutats en clau pluricultural: construcció del conflicte, experiències veïnals i gestió institucional, València: IAM.

BorJa, J. (2011). «Espacio público y derecho a la ciudad». Viento Sur, 116, pp. 39-59.

Brenner, N. Y Theodore, N. (2005). «Neoliberalism and the Urban Condition». City, 9(1), pp. 101-107.

CuCó, J. (2013). «La ciudad pervertida. Explorando la fórmula de renovación urbana de la Valencia glocalizada». En J. Cucó, J. (Dir.), La ciudad pervertida. Una mirada sobre la Valencia global (pp. 7-15). Barcelona: Anthropos.

- (2016). «Un barrio marginado no es un barrio marginal. A propósito de Nazaret (Valencia)». Revista de Dialectología y Tradiciones Populares, 71(1), pp. 151-171.

De la Haba, J. y Santamaría, E. (2004). «De la distancia y la hospitalidad: consideraciones sobre la razón espacial». Athenea Digital, 5. Recuperado de http://antalya.uab.es/athenea/num5/delahaba.pdf

Delgado, M. (1998). «Dinámicas identitarias y espacios públicos». Afers Internacionals, 43-44, pp. 17-33.

Delgado, M. (1999). «Anonimat i ciutadania: dret a la indiferència en contextos urbans». Revista catalana de sociologia 10, pp. 9-22.

GAJA, F. (2006). «Una mirada a la Ciutat de València: El boom de València 
o la ciutat com a espectacle». En VVAA. Llibre Verd del territori valencià, (pp. 201-213), València: Federació Escola Valenciana.

Giménez, C. (2005) «Convivencia Conceptualización y sugerencias para la praxis». Puntos de Vista. Cuadernos del Observatorio de las Migraciones y de la Convivencia Intercultural de Madrid, 1:7-31.

- (Dir.) (2015). Juntos por la convivencia. Claves del Proyecto de Intervención Comunitaria Intercultural. Barcelona: Obra Social La Caixa.

GofFMan, E. (1981[1959]). La presentación de la persona en la vida cotidiana, Buenos Aires: Amorrortu.

HaRvey, D. (2003). «The right to the city». International Journal of Urban and Regional Research, 27(4), pp. 939-941.

KeIтh, M. (2009). «Urbanism and city spaces in the work of Stuart Hall». Cultural Studies, 23(4), pp. 538-548.

Leal, J. Y Leyva, M. S. (2011). «El espacio público de los inmigrantes». ACE. Arquitectura, Ciudad y Entorno, 17, pp. 317-333.

Lefebvre, H. (1969[1968]). El derecho a la ciudad. Barcelona: Península.

López SALA, A. M. (2006). «Derechos de ciudadanía y estratificación cívica en sociedades de inmigración». En J. Campoy, I. (Ed), Una discusión sobre la universalidad de los derechos humanos y la inmigración, (pp. 129-151), Madrid: Dykinson.

Low, S., TAPlin, D, y Sheld, S. (2005). Rethinking urban parks. Public Space and Cultural Diversity. Austin: University of Texas Press.

Moncusí Ferré, A. y Llopis Goig, R. (2012) «Inmigrantes latinoamericanos y fútbol en España. El caso de las ligas de fútbol amateur organizadas por latinoamericanos en la ciudad de Valencia». En G. Alonso, G. y L. Escala, L. (Coords.), Offside. Fuera de Juego. Fútbol y Migraciones en el Mundo Contemporáneo, (pp. 87-108). México: Colef.

- Hernández Martí, G.M. (2013). «El río que nos lleva. El jardín del Túria como metáfora de la ciudad». En Cucó, J. (Dir.), La ciudad pervertida. Una mirada sobre la Valencia global, (pp. 141-162). Barcelona: Anthropos.

- Santamarina Campos, B. (2013). «De huertas y barracas a galaxias faraónicas. Percepciones sociales sobre la mutación de la ciudad de Valencia». Papers, 98(2), pp. 365-391.

Segura, R. (2013). «Lo público como lugar practicado. Regulaciones sociales, temporalidades colectivas y apropiación diferencial de la ciudad». En M. Fernández y M. D. López (Eds.), Lo público en el umbral, (pp. 18-46). La Plata: Universidad Nacional de La Plata. 
Simmel, G. (1986[1908]). Sociología. Estudios sobre las formas de socialización. Madrid: Alianza.

Sorribes, J. (2015). Valencia 1940-2014: Construcción y destrucción de la ciudad. Valencia: PuV.

Tonnelat, S. (2010). «The Sociology of Public Spaces». En Wang Hongyang, Savy Michel and Zhai Guofang (Eds.). Territorial Evolution and Planning Solution: Experiences from China and France. Paris: Atlantis Press.

— Milliot. V. (2013). «Contentious policing in Paris. The street as a space for emotional public solidarity». En R. Lippert y K. Walby (Eds). Policing cities: urban securitization and regulation in a $21^{\text {st }}$ Century World, (pp. 191-204), London: Routledge.

Torres Pérez, F. (2005). «Los espacios públicos en la ciudad multicultural. Reflexiones sobre dos parques en Valencia». Puntos de Vista: Cuadernos del Observatorio de las Migraciones y la Convivencia Intercultural de la Ciudad de Madrid, 1, pp. 33-49.

- (2008). «Los nuevos vecinos en la plaza. Inmigrantes espacios y sociabilidad pública». AIBR. Revista de Antropología Iberoamericana, 3(3), pp. 366-397.

- (2011). La inserción de los inmigrantes. Luces y sombras de un proceso, Madrid: Agora.

- García Pilán, P. (2013). «La ciudad ocultada. Desigualdad y precarización en la Valencia global». En J. Cucó (Dir), La ciudad pervertida. Una mirada sobre la Valencia global, (pp. 163-188). Barcelona: Anthropos.

- Moncusí Ferré, A. y Esteban, F. O. (2015). «Crisis, convivencia multicultural y "efectos de barrio". El caso de dos barrios de Valencia». Migraciones, 37, pp. 217-238.

- Moncusí Ferré, A. (e. p.). «Gentrificació, precarització i dinàmiques veïnals en barris pluriculturals. una reflexió des de València». En A. Moncusí, F. Torres y H. Fioravanti (Eds), Barris i ciutats en clau pluricultural: construcció del conflicte, experiències veïnals i gestió institucional. València: IAM.

Zambra-Álvarez, A. ET AL. (2017), «Mapeando cl conocimiento local: Experiencias de cartografía participativa en el sur de Chile». AUS. Arquitectura/Urbanismo/Sustentabilidad, 20, pp. 20-27.

Zukin, S. (2009). «Changing Landscapes of Power: Opulence and the Urge for Authenticity». International Journal of Urban and Regional Research, 33(2), pp. 543-553. 